\title{
Administrative Transparency in Public Secondary Schools in Jordan
}

\author{
Dr-Khaled Serhan
}

The University Of Jordan

doi: 10.19044/esj.2016.v12n13p157 URL:http://dx.doi.org/10.19044/esj.2016.v12n13p157

\begin{abstract}
This study aimed to probe the degree to which public secondary school principals exercise administrative transparency in Jordan, as well as study the effect gender, educational background and years of experience have on the degree of exercising it. The study population consisted of all public secondary school principals working at the Directorate of Education in First Zarqa area for the academic year 2015-2016. The study sample consisted of (263) teachers who were selected randomly. A questionnaire was developed consisting of (22) items using appropriate statistical methods to obtain the results.

The study results showed that the degree of exercising administrative transparency was moderate in the fields of Information Clarity and Administrative Accountability, while it was low in the Participation field. In light of the results, the study presented a set of recommendations, such as raising awareness among school principals of the importance of exercising administrative transparency across all of its domains.
\end{abstract}

Keywords: Administrative transparency, public secondary schools

\section{Introduction}

The developments and changes in management practices such as communication mediums, information transfer speed and accessibility contributed to the emergence of new management practices. Transparency is considered one of the modern management concepts for which accountability towards its application became a differentiator that successful managers pride themselves in.

Transparency is a differentiator that influences management policy according to specific mechanisms that the service recipient looks into, and it sets out the responsibilities among the various levels of management, which in turn contribute to strengthening accountability (Mikhlafi, 2013). 
Exercising transparency also ensures that information reaches those who need it, which helps in making and evaluating decisions. Thus transparency is associated with: Disclosure, clarity, and participation (Daibes, 2004).

Toukhi (2002) considers that management in transparency means "commitment by public administration organizations to disclosure, openness and clarity in operations through enforcing them and subjecting them to accountability."

In this area, Balkin (1998) shows that transparency is not merely provision of information only, but includes participation and responsibility. Moreover, Vaughn (Vaughn, 2000) confirms that transparency includes providing information on facts of public concern, including citizens' ability to participate in decision-making, and accountability towards it.

Pioneers of management thinking have called for the importance of expending much effort to resolve management issues and identifying obstacles that face administrative development such as management corruption, routine, and ambiguity in work methods and procedures. Exercising transparency in management operations comes as one of the important issues which must be observed in administrative practices among the various management apparatus (Lozi, 2002)

\section{The concept of transparency}

Transparency International (2006) defines transparency as the clarity of the regulations and procedures within the organization on one hand, and between the organization and the citizens using their services on the other hand. This includes open procedures, goals and targets in the work of the institution. It also includes ensuring the right of citizens to obtain the necessary information.

Florini (1998) shows that transparency is contrary to secrecy. Secrecy means to hide actions intentionally and deliberately. (Cotterel, 1999) defines transparency as an instrument which provides information on the facts that concern the public, the ability of citizens to participate in political decisions, and the responsibility of the government in the legal process. Toukhi (2014) defined it as commitment to clarity in doing business with supervision and accountability.

\section{The fields of transparency and its dimensions}

Like administrative concepts, the application of the concept of transparency in administration requires the recognition of the dimensions, areas of application and the limits of this application.

It was shown by Al-Otaibi (2009) the dimensions of transparency are: Clarity, openness, accuracy, ease of access to information; and participation 
in decisions which are made between the various administrative levels, not inconsistent with the supreme public interest. Transparency does not require the disclosure of secrets that could affect the security of the state or individuals.

Administration with transparency must include clarity of information, participation in decision-making followed by accountability for achieving results (Ramzi, 2013).

Administrative transparency includes a range of dimensions: Management of information, administration and communication, participation, and accountability (Toukhi, 2014)

Clarity of information and participation in decision-making contribute to the employees' sense of belonging to the organization as participants in the decision-making, as it makes them feel the importance of their opinions by providing the information they need, thus allowing them to make proposals relating to the success of the work.

Applying transparency helps employees actively participate to develop and build self-reliance in achieving a better quality of performance by focusing on quality and increasing productivity at work (Lozi, 2002).

An important aspect of transparency is that it works to reduce ambiguity and uncertainty. It contributes to eradicate corruption and ambiguity of legislation. Its existence helps the empowerment of decisions issued from outside and inside the organization. It contributes to achieve the public's rights to understanding and knowledge through their participation, and helps them to understand the management of the internal data operations. Transparency is also concerned in educating citizens and informed them of the options available. It works as well in facilitating performance assessments (Tasha,2007).

It must be noted that applying transparency faces obstacles which vary depending on the nature of the organization, and the degree of awareness of officials and individuals. Despite the importance of participating in decision-making in the organization, this participation must be within specific controls, to give an opportunity for management to take the appropriate decision, which fits with the existing data in the enterprise.

On the other hand, the presence of negative legacies of previous administrative systems means that it requires a long time before starting the advancement of society and its institutions. The misinterpretation of information by its users, constitute an obstacle to the application of transparency (Fung, et al, 2007).

\section{Study Problem}

The study came to reveal the degree of transparency among principals from the standpoint of their teachers by: 
1- Giving importance to applying the concept of transparency in educational institutions in general and schools in particular. Many studies have emphasized the need for applying administrative transparency in schools.

2- Giving importance to the disclosure of management practices in schools, and whether they apply traditional management practices that do not fit the development and progress in various fields. The study came to reveal the degree of transparency of principals from the standpoint of their teachers.

\section{Objectives of the study}

This study aims to answer the following question: -

What is the degree of applying administrative transparency among public secondary schools' principals in Jordan, from the viewpoint of their teachers?

\section{The importance of the study}

- The importance of the practice of administrative transparency lies in providing clear information in a timely manner to its members allowing them to participate in decision-making. Thereby it would enhance the affiliation of individuals to their institutions and makes them an important part of it.

- Involvement in decision making in the industry enhances team work.

The importance of this study comes through the following: -

- Providing information on the degree of practicing administrative transparency among public secondary schools’ principals.

- The results of this study provides information about the needs of the Ministry center to determine the therapeutic and developmental programs required.

\section{Limits of the study}

The study was limited to teachers and Ministry of Education employees in public secondary schools of the Directorate of Education in the First Zarqa governorate for the scholastic year 2015-2016.

\section{Study terms}

Administrative transparency: One of the management practices that include the disclosure of information accurately and in a specific time. Moreover, it is to allow individuals to participate in decision-making. As well as accepting suggestions, feedback, and readiness for accountability. 


\section{Previous studies}

\section{First: Arab Studies:}

Irtimih (2005) study entitled "The transparency of the evaluation of the performance of employees in the Ministry of Education," a field study to evaluate the reality , the importance and obstacles of transparency. "The aim of study is to recognize the reality of the transparency of the evaluation, and the importance of transparency in the evaluation performance. Also, obstacles faced by the transparency of the evaluation, and the methods proposed and mechanisms to develop the level of transparency of the evaluation. The results of this study showed that workers in the Ministry of Education attitudes towards areas of study were satisfying especially in the aspect of the importance of transparency in the evaluation in improving the performance.

And the predominant leadership style in the Ministry of Education does not give an opportunity to participate in decision-making, which is one of the biggest obstacles facing the transparency evaluation. The Ministry of Education as well does not provide the support needed to establish the principle of transparency in the assessment.

Another study was done by Tasha (2007) entitled: "The degree of commitment to administrative transparency in the Ministry of Education in Kuwait from the perspective of workers in "aimed to identify the degree of commitment to transparency in the management of the Ministry of Education in Kuwait from the viewpoint of its employees. The study results show that the degree of commitment is fair for the transparent administrative areas and the instruments as a whole. And that there are differences statistically significant differences in the degree of commitment of administrative transparency due to the variables of gender and instrument in all areas in favor of males.

Amayreh (2008) conducted a study entitled: Administrative Transparency among Education Principals in Jordan and its relationship with both the pressure and psychological security for workers in directorates from the standpoint of these workers. The results showed that the level of transparency among education principals from the perspective of workers in the departments of Education was average in all fields. As financial resource management came more transparent field then comes the Department of Education. Third, the area of the Planning Department, and then the field of human resources management. The management of relations with the local community comes at the end.

Harb (2011) conducted a study entitled: The reality of administrative transparency and its requirements to apply it in Palestinian schools in the Gaza Strip. This study aimed to get to know the reality of administrative transparency, the requirements that it needs to be applied to the senior 
management in Palestinian schools in the Gaza Strip. And determine whether there are statistically significant differences in the respondents' answers between the information system, administrative communication, management, accountability, participation, and the procedures of applying this administrative transparency in those schools. The study results showed a commitment in practicing administrative transparency acceptable degree with administrators and academics that occupy managerial positions in Palestinian schools. And the presence of a statistically significant relationship between fields of study (information system, administrative and communication, management, accountability, participation, and work procedures) and the reality of administrative transparency in Palestinian schools.

\section{Second: - Foreign Studies}

McIvor (2002) study entitled "Internet technology and its role in supporting transparency in public sector organizations" This study aimed to investigate the importance of Internet technology in achieving transparency in public sector organizations, And the impact of the organizations interaction with the surrounding environment in general, and the beneficiaries of its services in particular. The results of this study showed that there is a great awareness among respondents about the importance of the proposals made by the government about the transition to e-government, which in turn will bring transparency. And the realistic application of this transparency is demonstrated through the entry of employees on the Internet, sending e-mails and electronic transaction services) for third parties.

Hancock \& Hellawell (2003) also conducted study aimed to identify the degree of transparency in the central academic administration treated in one of the modern schools in the United Kingdom with their superiors and their subordinates. The most important results of this study that the deans and department heads too heavily committed to the support of transparency and the free flow of information, but they have admitted that they are times, they follow secret ways, and they believe that this came against their will as a result of the need to do so.

Stephens (2007) study entitled "transparency of information management," aimed to describe the legal requirements for transparency in appointments and promotions in higher Swedish education institutions, through interviews with senior executives in those institutions, as well as content analysis of legal documents. The study results show that transparency is low in all stages of the procedure and documentation of appointments and promotions have shown. Also showed the emergence of 
points of weakness was the lack of transparency in certain matters arising from operations during the informal decision-making process.

Norman (2010) conducted study entitled: "The Impact of transparency and positivity in the confidence of the presidents and effectiveness" This study aimed to identify the impact of the adoption of transparency on the level of confidence in the president's subordinates and their perception of its effectiveness. The main results showed that the transparency of the President and the level of his mental abilities have positive impact on the degree of confidence of subordinates and their recognition of the level of effectiveness. Workers are more confident of the manager who trusts their decisions and provide them with the necessary decision-making information.

\section{Methods and procedures}

\section{The study methodology}

The study used a descriptive and analytical approach, and this was used as the instrument prepared by the researcher, depending on the previous literature on the subject of the study and through practical experience in dealing with respondents. Statistical software was used to analyze the results. The results where interpreted with a comparison to similar studies.

\section{The study population and sample}

The study population consisted of all teachers in public secondary schools in the Directorate of Education in the First Zarqa area for the scholastic year 2015-2016. The selected sample was randomly taken consisting of (263) teachers.

\section{Instrument veracity}

The instrument was checked by presenting it to a number of arbitrators and specialists in the educational field to determine the degree of affiliation of the paragraphs and their suitability within the areas that have been developed, and the degree of accuracy and clarity of the paragraphs. The instrument was stabilized across the (22) items.

\section{Instrument Consistency}

To check the consistency of the instrument, the consistency coefficient was calculated with the internal consistency method by using Cronbach's Alpha equation. The consistency coefficient was (0.84).

\section{Results of the study and discussion}

After the necessary statistical methods were used for each question of the survey, we will display results related to these questions. The results 
relating to the first question, which says: "What is the degree to which public secondary school principals practice transparency from the teachers' point of view?" It was as follows: -

Table (1) the degree of public secondary school principals' administrative transparency from the point of view of teachers (Clarity)

\begin{tabular}{|c|c|c|c|c|}
\hline Degree & $\begin{array}{c}\text { Standard } \\
\text { Deviation }\end{array}$ & Mean & Paragraph & No. \\
\hline High & 0.463 & 2.61 & $\begin{array}{c}\text { Administration provides information with } \\
\text { accuracy and credibility. }\end{array}$ & 1 \\
\hline Medium & 0.464 & 2.30 & $\begin{array}{c}\text { The Administration reviews information } \\
\text { before submission }\end{array}$ & 2 \\
\hline High & 0.494 & 2.40 & $\begin{array}{c}\text { The Administration provides the necessary } \\
\text { information in a timely manner }\end{array}$ & 3 \\
\hline High & 0.493 & 2.39 & $\begin{array}{c}\text { The information provided by the } \\
\text { Department fits the work procedures }\end{array}$ & 4 \\
\hline Low & 0.01 & 2.00 & $\begin{array}{c}\text { The information provided by the } \\
\text { Administration is updated on an ongoing } \\
\text { basis }\end{array}$ & 5 \\
\hline Low & 0.01 & 2.00 & $\begin{array}{c}\text { The Administration has sequence-based } \\
\text { system to provide the necessary } \\
\text { information }\end{array}$ & 6 \\
\hline High & 0.46 & 2.69 & $\begin{array}{c}\text { The Administration upholds the } \\
\text { confidentiality of forbidden information } \\
\text { that may be harmful }\end{array}$ & 7 \\
\hline
\end{tabular}

Table (2) the degree of public secondary school principals' transparency from the point of view of teachers (Participation)

\begin{tabular}{|c|c|c|c|c|}
\hline Degree & $\begin{array}{l}\text { Standard } \\
\text { Deviation }\end{array}$ & Mean & Paragraph & No. \\
\hline Medium & 0.463 & 1.69 & $\begin{array}{l}\text { The Administration encourages } \\
\text { employees to submit work-related } \\
\text { proposals }\end{array}$ & 1 \\
\hline Low & 0.464 & 1.31 & $\begin{array}{c}\text { The Administration cares about the } \\
\text { proposals submitted and studies } \\
\text { them }\end{array}$ & 2 \\
\hline Medium & 0.02 & 2.01 & $\begin{array}{l}\text { The Administration discussed the } \\
\text { proposals submitted with the } \\
\text { persons concerned }\end{array}$ & 3 \\
\hline Low & 0.463 & 1.32 & $\begin{array}{l}\text { The Administration involves } \\
\text { teachers in decision-making. }\end{array}$ & 4 \\
\hline Medium & 0.493 & 1.68 & $\begin{array}{l}\text { Administration is working on } \\
\text { involving school personnel in } \\
\text { supporting decisions }\end{array}$ & 5 \\
\hline Medium & 0.784 & 1.69 & $\begin{array}{l}\text { The Administration encourages } \\
\text { employees to detect errors }\end{array}$ & 6 \\
\hline Low & 0.465 & 1.60 & $\begin{array}{c}\text { The Administration distributes } \\
\text { authority at work }\end{array}$ & 7 \\
\hline Medium & 0.493 & 2.01 & $\begin{array}{l}\text { The Administration allows all its } \\
\text { members to participate and supports } \\
\text { their participation and provides } \\
\text { feedback to them }\end{array}$ & 8 \\
\hline
\end{tabular}


Table (3) the degree of public secondary school principals' transparency from the point of view of teachers (Accountability)

\begin{tabular}{|c|c|c|c|c|}
\hline Degree & $\begin{array}{c}\text { Standard } \\
\text { Deviation }\end{array}$ & Mean & Paragraph & No. \\
\hline Medium & 0.463 & 2.30 & $\begin{array}{c}\text { The school has a clear mechanism } \\
\text { of accountability }\end{array}$ & 1 \\
\hline High & 0.494 & 2.60 & $\begin{array}{c}\text { The accountability mechanisms are } \\
\text { announced to everyone }\end{array}$ & 2 \\
\hline High & 0.460 & 2.69 & $\begin{array}{c}\text { Accountability mechanisms fit with } \\
\text { work interests }\end{array}$ & 3 \\
\hline Medium & 0.02 & 2.01 & Accountability mechanisms are just & 4 \\
\hline Medium & 0.467 & 2.3 & $\begin{array}{c}\text { Administration accountability } \\
\text { applied to all individuals without } \\
\text { bias. }\end{array}$ & 5 \\
\hline Medium & 0.464 & 1.69 & $\begin{array}{c}\text { Accountability process adopted by } \\
\text { the Administration is based on } \\
\text { correct information. }\end{array}$ & 6 \\
\hline High & 0.494 & 2.38 & $\begin{array}{c}\text { Administration provides staff } \\
\text { members with explanations before } \\
\text { the applying sanctions }\end{array}$ & 7 \\
\hline
\end{tabular}

The results related to the degree of administrative transparency in public secondary schools from the teachers' point of view were:

The degree of practice in terms of the clarity of the information was medium $($ Mean $=2.34)$

In terms of participation was low (mean $=1.9)$,

And it came as medium (mean $=2.28$ ) in terms of management accountability.

This may be attributed to the instructions that the principals are following which the Ministry of Education issues. The spread of social media may have contributed to the ease of dissemination of information and its circulation among teachers.

In terms of participation in the decision-making, the results were low because of the prevailing culture - according to the results - that the principals are still practicing traditional management in terms of exclusiveness in the decision-making, and not to involving teachers in it, and this was confirmed by Fang (Fung, et al 0.2007). Furthermore, the findings come to agree with the study of Tasha \& Hawamdeh (2009) and the study of Goran (2007) and the study of Hancock \& Hellawell (2003).

\section{Recommendations}

-The need to raise awareness of the importance to school principals of exercising transparency in all sectors, and that this practice supports the achievement of the objectives of their schools. 
-Confirmation from the Ministry of Education to school principals of the need to involve and train teachers to participate in decision-making.

\section{References:}

\section{First: - Arabic references}

Amayreh, Adnan Khaled Mahmud (2008). Administrative transparency among education managers in Jordan and its relationship to both the pressure and psychological security for workers in Directorates. Unpublished doctoral dissertation, Amman Arab University for Graduate Studies, Amman, Jordan. Al-Otaibi, Falah Nada (2009). Transparency in government agencies. Unpublished MA Thesis, College of Business Administration, King Saud University, Riyadh.

Daibes, Manal (2004), the extent of the application of transparency in the Jordanian ministries centers, unpublished Master Thesis, Yarmouk University, Jordan.

Fakhoury, Yara Fred (2009), the degree of perception and practice of public school administrators in the southern governorates of Jordan to the concept of transparency. Unpublished MA Thesis, University of Mutah.

Harb, Naima Mohammed (2011). The reality of administrative transparency requirements applied in Palestinian schools in the Gaza Strip. Unpublished MA Thesis, Islamic school, Gaza, Palestine.

Irtimih, Mageda Suliman (2005). Transparency of the evaluation of the performance of employees in the Ministry of Education: An Empirical Study of the reality and the importance of transparency and obstacles. Unpublished MA Thesis, Yarmouk University, Jordan.

Lozi, Mohammed (2002). Management Development, Amman, Jordan: Dar Wael for Publishing and Distribution.

Mikhlafi, Seif Fouad Abed Al-Ghani, (2013) the principle of transparency and the fight against corruption to ensure the liberalization of world trade, the first edition, Dar al-Zahra Publishing and Distribution, Riyadh.

Ramzi, Fahad Abed Al-Rahman Misfer, (2013), the administration transparent to the managers of Education offices in Mecca from the perspective of managers and supervisors, Master, Um Al Qura University. Tasha, Ghoneim Hmoud \& Hawamdeh, Basem Ali. (2009). Degree of commitment to transparency in the management of the Ministry of Education in Kuwait from the standpoint of employees, Journal of Education, No. 93, Vol. (24), 15:18.

Tasha, Ghoneim Hmoud (2007). Degree of commitment to transparency in the management of the Ministry of Education in Kuwait from the viewpoint of its staff. Unpublished MA Thesis, Amman Arab University for Graduate Studies, Amman, Jordan. 
Toukhi, Sami, (2014). Transparency in the conduct of public affairs the way for development and administrative reform, Arab Renaissance Publishing House, Cairo.

Toukhi, Sami(2006). Leaders transparent: the road of development and administrative reform. A comparative study. Cairo: Dar Arab renaissance.

Toukhi, Sami (2002). Management transparency and empowerment in the transport sector in Egypt, Journal of Research and Information Center Management Research, Sadat Academy for Management Sciences, Volume IV. Egypt.

\section{Second: - foreign references:}

Balkin, J.M. (1998). Cultural Software: A Theory of Ideology. New Haven, CT: Yale University Press.

Florini, Ann M.,(1998) . "The End of Secrecy." Foreign Policy(111):50-63. Forthcoming. Transnational Civil Society. Tokyo: Japan Center for International Exchange.

Fung, et al,(2007). Full Disclosure: The perils and Promise of Transparency, Cambridge University Press, Britain .

Goran, S,(2007). legal requirements for transparency in appointments and promotions in Swedish higher education institutions, International Journal of Public Sector Management. vol.20, Issue:2.

Hancock, N\& Hellawell, D(2003). Academic Middle Management in Higher Education: a Game of Hide and Seek?. Journal of Higher Education Policy and Management vol.25 (1), p4-13.

McIvor, Ronan, et al.,(2002) Internet Technologies: Supporting Transparency in the Public Sector, International Journal of Public Sector Management.vol.15, No.3, PP. 170 -187.

Norman, Steven., et al.,(2010 ). The impact of positivity and transparency on trusting, leaders and their perceived Effectiveness, Leadership quarterly 21,University of Nebraska united states, Elsevier.

Stephens, R, Todd. ( 2007 ). Transparency Of Data Management. DM Review, Vol.17, Issu10, October, p 38.

Wilkinson, et al.,(2010 ). The Oxford Handbook of Participation in Organizations: Conceptualizing Employee Participation in Organizations, Oxford University Press, New York, first Edition. 